\title{
Effect of prior loading cycles on vertical bearing capacity of clay
}

\section{Cristina Vulpe PhD}

Research Associate, Centre for Offshore Foundation Systems - M053, University of Western Australia, Perth, WA, Australia

\section{David J. White PhD}

Shell EMI Professor of Offshore Learning, Centre for Offshore Foundation Systems - M053, University of Western Australia, Perth, WA, Australia

The strength of a foundation on soft clay rises over time due to consolidation under the applied load. This effect can be advantageous in design. Previous studies have identified relationships between the level of monotonic vertical preload, as a proportion of the initial bearing capacity, and the subsequent consolidated bearing capacity. This study explores the influence of cycles of preloading by way of centrifuge model tests, and shows that repeated preloading leads to a further gain in bearing capacity. The gains are more significant if the preloading involves two-way cycles. For the cases explored in this study, the cyclic effect typically adds $\mathbf{5 0} \%$ to the gain in bearing capacity caused by the same preload applied monotonically.

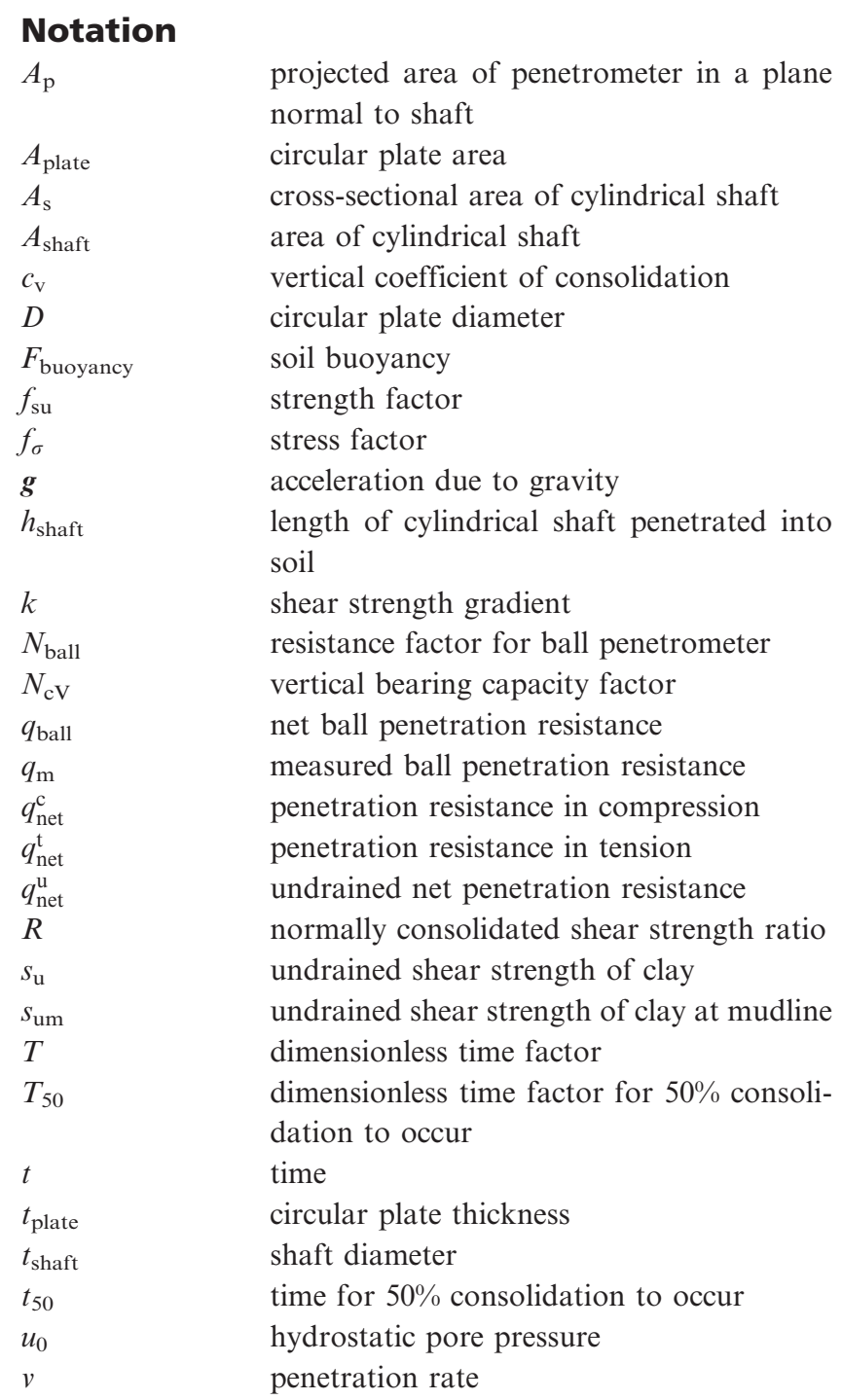

$\begin{array}{ll}v^{*} & \begin{array}{l}\text { normalised velocity } \\ z\end{array} \\ \alpha & \text { depth } \\ & \text { net area ratio for ball penetrometer } \\ \gamma^{\prime} & \text { effective unit self-weight of soil } \\ \Delta q_{\text {net }}^{\mathrm{c}} & \text { increase in penetration resistance in com- } \\ & \text { pression } \\ \Delta q_{\text {net }}^{\mathrm{t}} & \text { increase in penetration resistance in tension } \\ \Delta q_{\mathrm{pl}}^{\prime} & \text { plastic stress component } \\ \Delta s_{\mathrm{u}} & \text { increase in undrained shear strength after } \\ & \text { consolidation } \\ \Delta u & \text { excess pore water pressure } \\ \sigma_{\mathrm{v} 0} & \text { in situ total vertical stress } \\ \sigma_{\mathrm{v} 0}^{\prime} & \text { in situ effective vertical stress }\end{array}$

\section{Introduction}

The undrained bearing capacity of a shallow foundation on soft clay varies with time due to consolidation caused by the loading condition. These changes in bearing capacity can be advantageous. In the offshore environment, the dead weight 'preloading' of the structure is sometimes relied on to enhance the strength and bearing capacity of the foundation (e.g. Watson and Humpheson, 2007). This strength enhancement is useful if the structure is enlarged or the design environmental load revised during the operating life. Onshore, it has become increasingly common to reuse existing foundations when urban sites are redeveloped (Butcher et al., 2006; Chapman et al., 2007). In these conditions, it may be beneficial to account for consolidation-induced enhancement of the foundation bearing capacity.

This study is concerned with soft, normally consolidated (NC) clay prevalent in deep water offshore, and sometimes 
International Journal of Physical Modelling in Geotechnics Volume 14 Issue 4
Effect of prior loading cycles on vertical bearing capacity of clay Vulpe and White encountered onshore in estuarine environments. When a foundation is installed on soft clay and dead weight or preload is applied, excess pore pressure is generated in response to the increased total stress and potentially also from the shearing deformation. Previous research studies have identified the increase in undrained vertical bearing capacity from sustained monotonic preloading (Bransby, 2002; Gourvenec et al., 2014; Zdravkovic et al., 2003).

In practice, the load applied to a foundation during the working life may include a significant cyclic component. Examples include offshore structures that are exposed to hydrodynamic loading from wind and waves and changing self-weight from oil storage, or the foundations for tanks, stockpiles and subsea equipment that experience changing loads depending on the operating conditions. As these operating conditions change during the life of the facility, there may be opportunities to utilise the enhanced bearing capacity caused by consolidation.

Previous research on cyclic loading of coarse-grained soils (Andersen, 2009; Bjerrum, 1973) and fine-grained soils (Andersen, 2004; Hyde and Ward, 1986; Koutsoftas, 1978; Togrol and Güler, 1984; van Eekelen and Potts, 1978) has investigated the degradation of strength due to excess pore pressure generation, but the subsequent consolidation hardening effect has received only limited attention (France and Sangrey, 1977; Hodder et al., 2013; White and Hodder, 2010).

The purpose of the present study is to extend previous work on monotonic preloading and to explore how cyclic preloading can enhance the bearing capacity of foundations on soft clay.

\section{Methodology}

\subsection{Apparatus}

The experimental programme was carried out in the beam centrifuge at the University of Western Australia (UWA). The physical characteristics of the equipment are described by Randolph et al. (1991). The swinging platform radius is $1.8 \mathrm{~m}$ and the strongbox measures $0.690 \mathrm{~m}$ by $0.390 \mathrm{~m}$ in plan with a depth of $0.325 \mathrm{~m}$. The tests described in the current paper were carried out at an acceleration of $25 \mathrm{~g}$, on a model seabed consisting of UWA kaolin clay.

\subsection{Model foundation and instrumentation}

One shallow, circular foundation model was fabricated from aluminium for the tests; the dimensions of the model and of the resulting prototype are summarised in Table 1 . The model consists of a $0.04 \mathrm{~m}$ diameter circular plate connected to a cylindrical shaft with diameter $t_{\text {shaft }}=0.01 \mathrm{~m}$ (Figures 1 and 2). Since the tests were carried out at $25 \mathrm{~g}$, the prototype circular foundation has a diameter of $1 \mathrm{~m}$. The prototype dimensions analysed in this study are not intended to represent

\begin{tabular}{lcc} 
& Model: $\mathrm{m}$ & Prototype: $\mathrm{m}$ \\
\hline Plate diameter & 0.04 & 1.0 \\
Plate thickness & 0.004 & 0.1 \\
Shaft diameter & 0.01 & 0.25 \\
\hline
\end{tabular}

Note: Prototype dimensions for $\mathbf{2 5 g}$

Table 1. Foundation geometry

a specific offshore application, although foundation elements of $1 \mathrm{~m}$ in typical dimension are often used to support subsea structures.

The model is equipped with one pore pressure transducer (PPT) encased in the shaft and set flush with the underside of the circular plate. The purpose of the PPT is to monitor the excess pore pressure development during installation and subsequent dissipation underneath the circular plate.

Load- and displacement-controlled simulations were carried out by vertically attaching a $3 \mathrm{kN}$ capacity load cell and a linear variable displacement transducer (LVDT) to the model through a rigid loading arm, which is connected to a onedimensional actuator. Load- and displacement-controlled operations were performed using the package actuator control system (PACS), an in-house software developed at UWA (De

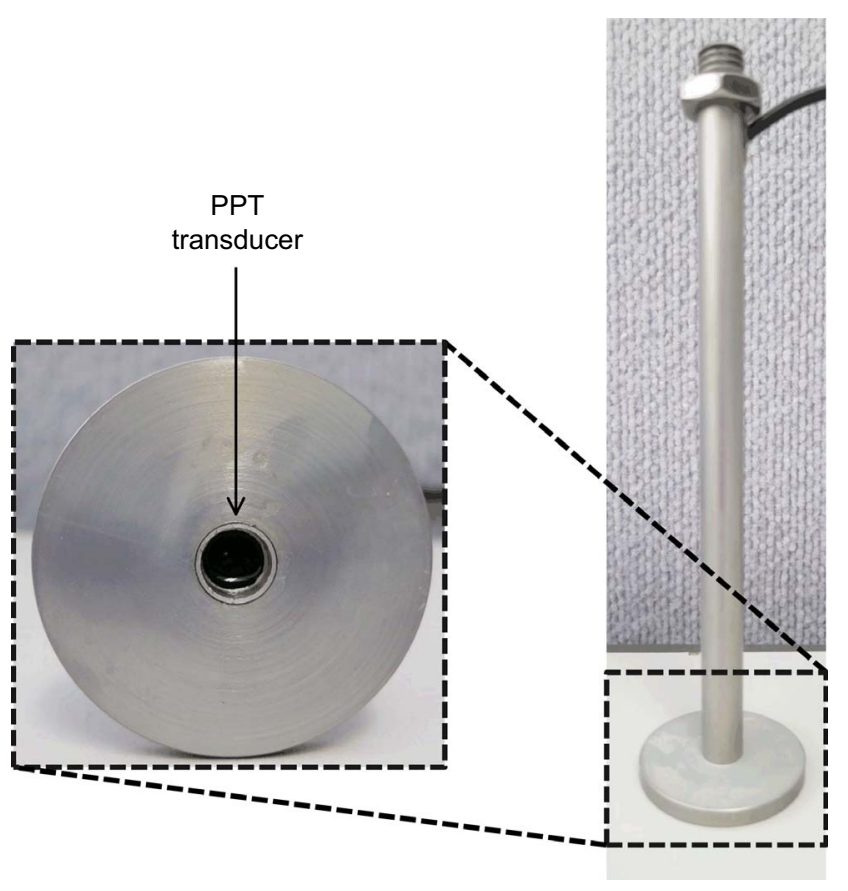

Figure 1. Model circular shallow foundation 
Effect of prior loading cycles on vertical bearing capacity of clay Vulpe and White

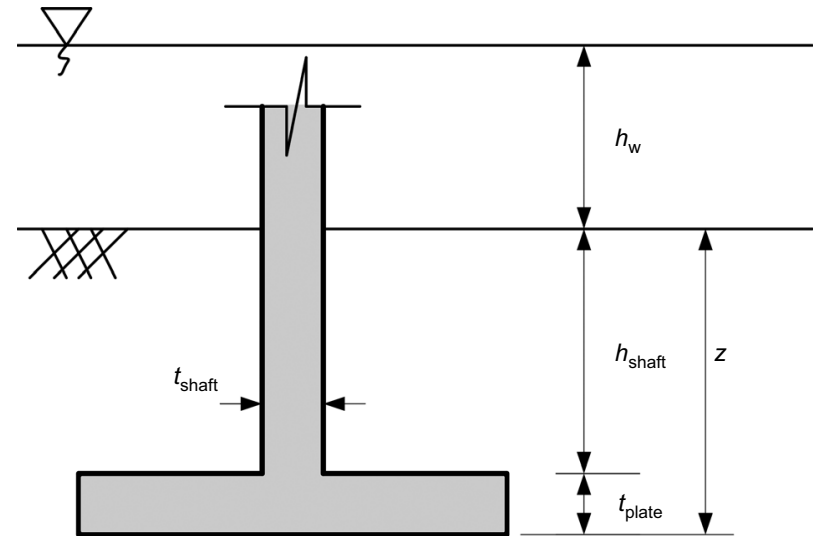

Figure 2. Circular plate geometry

Catania et al., 2010), and data acquisition was performed using the Digidaq software (Gaudin et al., 2009).

\subsection{Sample preparation}

All the tests documented in the current study were conducted on kaolin clay, normally consolidated from slurry in the centrifuge. The mechanical properties of the kaolin used in the tests have been thoroughly investigated by previous researchers (Chen, 2005; Gourvenec et al., 2009; Stewart, 1992) and are summarised in Table 2.

The sample was prepared by mixing dry kaolin powder with water to form a slurry with a moisture content double the liquid limit (LL). While mixing the slurry in a barrel mixer, vacuum was applied for de-aeration. Afterwards, the slurry was transferred to the strongbox overlying a $15 \mathrm{~mm}$ thick sand drainage layer. A head of surface water was maintained over the sample at all times. The sample was spun at $25 \boldsymbol{g}$ for 4 days (model scale) to achieve primary consolidation. Lastly, $<5 \mathrm{~mm}$ of the sample was scraped off the top in order to create a perfectly flat testing surface, which had the effect of creating a very slight strength intercept at the mudline.

\begin{tabular}{lcc}
\hline Property & Symbol & Magnitude \\
\hline Liquid limit: \% & $\mathrm{LL}$ & 61 \\
Plastic limit: \% & $\mathrm{PL}$ & 27 \\
Specific gravity & $G_{\mathrm{s}}$ & $2 \cdot 6$ \\
Angle of internal friction: degrees & $\varphi$ & 23 \\
Virgin compression index & $\lambda$ & 0.205 \\
Recompression index & $\kappa$ & 0.044 \\
Coefficient of consolidation & $c_{\mathrm{v}}$ & $2 \cdot 6$
\end{tabular}

Table 2. Mechanical properties of kaolin clay (Stewart, 1992)
All of the PPT results are presented as excess pore pressures, so the results are independent of the height of the head of surface water over the soil sample.

The shear strength profile of the soil sample was determined by means of piezoball testing (Chung and Randolph, 2004; Low et al., 2007). The tests were carried out at a rate of $0 \cdot 1 \mathrm{~mm} / \mathrm{s}$, ensuring undrained conditions (Randolph and Hope, 2004). The initial penetration resistance measured by the piezoball was corrected for unequal pore pressure and overburden pressure following the expression defined by Chung and Randolph (2004)

1. $\quad q_{\text {ball }}=q_{\mathrm{m}}-\left[\sigma_{\mathrm{v} 0}-u_{0}(1-\alpha)\right] \frac{A_{\mathrm{s}}}{A_{\mathrm{p}}}$

where $q_{\mathrm{m}}$ is the measured penetration resistance, $\sigma_{\mathrm{v} 0}$ is the in situ total overburden stress, $u_{0}$ is the hydrostatic pressure, $\alpha=$ $0 \cdot 85$ and $A_{\mathrm{s}} / A_{\mathrm{p}}=0 \cdot 1$ (Low et al., 2010). The undrained shear strength, $s_{\mathrm{u}}$, is back-calculated from the net penetration resistance, $q_{\text {ball }}$

2. $s_{\mathrm{u}}=\frac{q_{\text {ball }}}{N_{\text {ball }}}$

where $N_{\text {ball }}=11 \cdot 3$, which is a typical $N$-factor for piezoball penetration tests (Colreavy et al., 2010; Low et al., 2010) and in normally consolidated soil can be adopted as a constant value over the entire sample depth (Gourvenec et al., 2009; Low et al., 2010). The resulting shear strength profile is shown in Figure 3 and given by the following expression

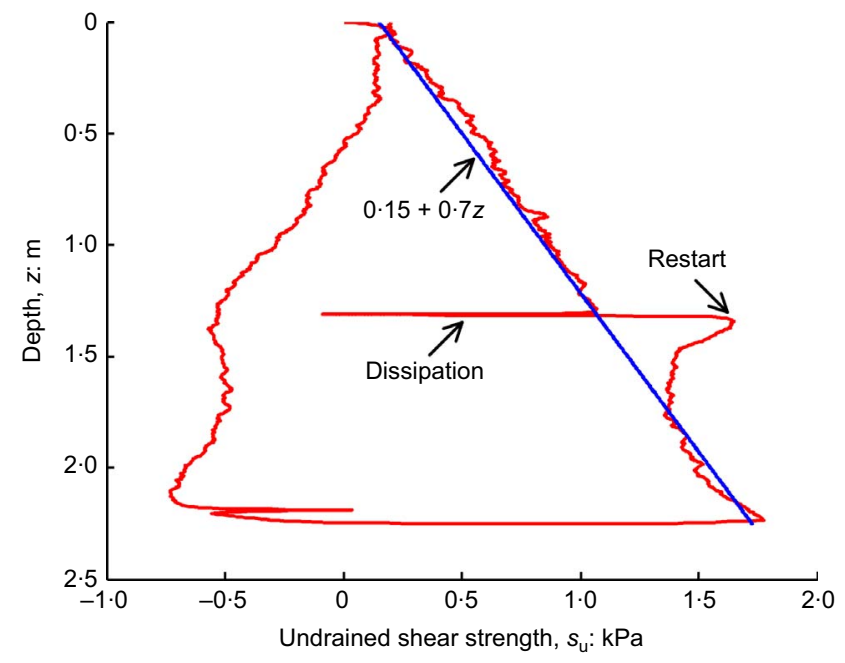

Figure 3. Calculated undrained shear strength from cyclic piezoball test 
International Journal of Physical Modelling in Geotechnics

Volume 14 Issue 4
Effect of prior loading cycles on vertical bearing capacity of clay

Vulpe and White
3. $s_{\mathrm{u}}=s_{\mathrm{um}}+k z$

where $s_{\mathrm{u}}$ represents the undrained shear strength at depth $z, s_{\mathrm{um}}$ is the undrained shear strength at the mudline and $k$ is the strength increase per unit depth. The profile is fitted with Equation 3 by $k=0.70 \mathrm{kPa} / \mathrm{m}$ and $s_{\text {um }}=0.15 \mathrm{kPa}$, essentially modelling an $\mathrm{NC}$ soil, typical of offshore conditions.

A dissipation stage was included in the piezoball test in order to determine the coefficient of consolidation, $c_{\mathrm{v}}$. Based on the work by Low et al. (2007), a representative dimensionless time factor is chosen, namely $T_{50}=0 \cdot 3$, which is used to determine the coefficient of consolidation for the current piezoball test. It results from $c_{\mathrm{v}}=D^{2} T_{50} / t_{50}$ that $c_{\mathrm{v}}=3.3 \mathrm{~m}^{2} /$ year, which is well within the expected values for UWA kaolin clay based on previous Rowe cell testing (Chen, 2005; Gourvenec et al., 2009).

\subsection{Experimental programme}

The experimental programme consisted of six tests summarised in Table 3 and shown schematically in Figure 4. A base case test, PF1, was carried out in order to corroborate the initial undrained shear strength, $s_{\mathrm{u}}$, and to provide a penetration resistance profile, $q_{\text {net }}^{\mathrm{u}}$, against which all the other test results are compared. A programme of tests involving monotonic and cyclic preloading was devised. The variables investigated included the type of cyclic vertical preloading (periodic or continuous) and the range (one-way or two-way). After the specified preloading process, the foundation was failed in compression for all tests (PF2, PF3, PF4 and PF4e) except for test PF2e (Figure 4(e)) which was failed in tension.

All penetration and extraction stages were carried out at a rate of $v=0 \cdot 1 \mathrm{~mm} / \mathrm{s}$ to ensure undrained conditions within those movements. Taking into account that $c_{\mathrm{v}}=3.3 \mathrm{~m}^{2} /$ year, the resulting normalised velocity $v^{*}=v D / c_{\mathrm{v}}$ is equal to 38 , confirming undrained conditions (Finnie and Randolph, 1994) (where
$D=0.04 \mathrm{~m}$ represents the drainage path equal to the model plate diameter).

PF1 was performed solely under displacement control at a rate of $0.1 \mathrm{~mm} / \mathrm{s}$ to determine the full undrained penetration response (Figure 4(a)). The rest of the tests were performed under displacement control to depth $z=0.5 \mathrm{~m}$, after which the actuator was switched to load control. A specified load sequence was then imposed, during which consolidation of the surrounding soil occurred.

During test PF2, the vertical load was maintained constant and the consolidation step was considered finished when the excess pore pressure $\Delta u$ reduced to $<0.6 \mathrm{kPa}$ which was after $10000 \mathrm{~s}$ (Figure 4(c)). This represents $>95 \%$ dissipation of the initial excess pore pressure, so a longer duration of dissipation would have negligible effect. For consistency, this period was then adopted for the consolidation step of all subsequent tests. Following the consolidation step of PF2, the actuator was switched back to displacement control and the foundation was failed under a controlled penetration rate of $0.1 \mathrm{~mm} / \mathrm{s}$. Test PF3 followed a similar process but with a regime of five periodic preload cycles with near-complete primary consolidation $(\Delta u<0.6 \mathrm{kPa})$ reached after each load and unload stage of the cycles (Figure 4(b)). Tests PF4 (Figure 4(d)) and PF4e (Figure 4(f)) underwent continuous one-way and two-way cyclic preloading during the consolidation stage, until a steady embedment was reached; the foundation was then failed in compression. During PF4 and PF4e all cycles were performed with a period of $10 \mathrm{~s}$ at model scale (Table 4). These cycles are sufficiently rapid to be effectively undrained within each cycle, as would be the case in prototype conditions, but not so fast that the behaviour is also influenced by inertial effects.

The time history for all tests are schematically represented in Figure 5, where $q_{\mathrm{net}}^{\mathrm{c}}$ and $q_{\text {net }}^{\mathrm{t}}$ represent the gain in net penetration resistance in compression and tension, respectively.

\begin{tabular}{lllll}
\hline & & \multicolumn{2}{c}{ Pre-loading regime } & \\
\cline { 3 - 4 } Test name & Pre-load type & \multicolumn{2}{c}{ Cycle } & Failure mode \\
\cline { 3 - 4 } & & Type & Range & Compression \\
\hline PF1 & None & - & - & Compression \\
PF2 & Monotonic & - & - & Compression \\
PF3 & Cyclic & Periodic & One-way & Compression \\
PF4 & Cyclic & Continuous & One-way & Tension \\
PF2e & Monotonic & - & - & Compression
\end{tabular}

Table 3. Experimental programme 
Effect of prior loading cycles on vertical bearing capacity of clay Vulpe and White

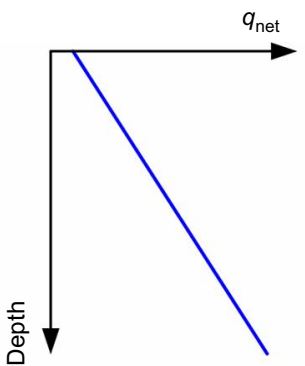

(a)

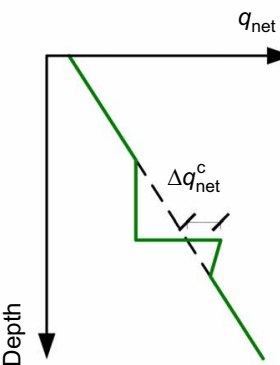

(c)

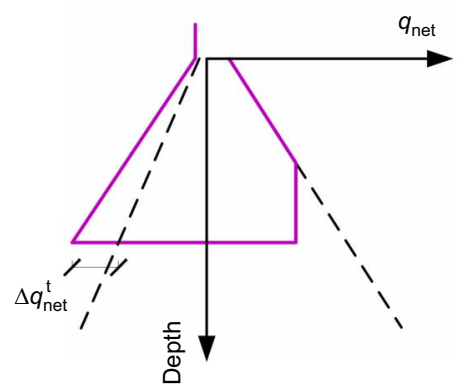

(e)

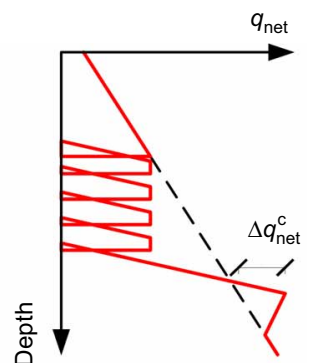

(b)

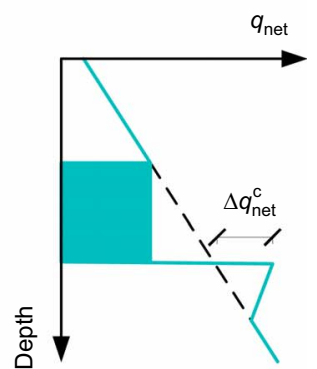

(d)

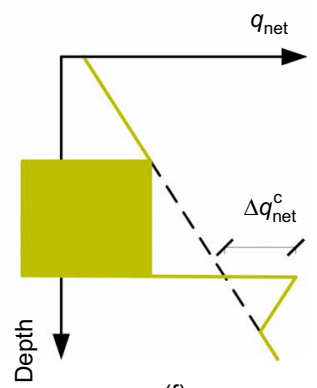

(f)
Figure 4. Schematic diagram of centrifuge testing programme; net resistance plotted against depth: (a) PF1; (b) PF3; (c) PF2; (d) PF4; (e) PF2e; (f) PF4e

\section{Foundation results: monotonic cases}

\subsection{No preload}

The undrained net penetration resistance, $q_{\text {net }}^{\mathrm{u}}$, is given by

4. $q_{\text {net }}^{\mathrm{u}}=q_{\mathrm{m}}-\frac{F_{\text {buoyancy }}}{A_{\text {plate }}}$

where $q_{\mathrm{m}}$ is the measured penetration resistance divided by the plate area, $A_{\text {plate }}$, and $F_{\text {buoyancy }}$ is the soil buoyancy term. This

\begin{tabular}{lcc}
\hline & Model & Prototype \\
\hline Period: $\mathrm{s}$ & 10 & 6250 \\
Frequency: $\mathrm{Hz}$ & 0.1 & 0.00016
\end{tabular}

Table 4. Centrifuge testing period and frequency is represented by the submerged weight of the kaolin soil displaced by the circular plate and the cylindrical shaft. The correction for soil buoyancy is given by

5. $F_{\text {buoyancy }}=\left\{\begin{array}{c}\gamma^{\prime} z A_{\text {plate }}, \quad \text { if } z<t_{\text {plate }} \\ \gamma^{\prime}\left[t_{\text {plate }} A_{\text {plate }}+\left(z-t_{\text {plate }}\right) A_{\text {shaft }}\right], \quad \text { if } z \geq t_{\text {plate }}\end{array}\right.$

where $A_{\text {plate }}$ and $A_{\text {shaft }}$ represent the areas of the circular plate and cylindrical shaft respectively; $t_{\text {plate }}$ is the plate thickness; $\gamma^{\prime}$ is the effective unit weight of soil.

Figure 6 presents the undrained vertical bearing capacity factor, $N_{\mathrm{cV}}$, obtained from the base case test, PF1. The vertical bearing capacity factor resulting from the measured resistance is defined as

6. $N_{\mathrm{cV}}=\frac{q_{\mathrm{net}}^{\mathrm{u}}}{s_{\mathrm{u}}}$

Bearing capacity factors determined from numerical studies involving large-deformation finite-element analysis - which captures the soil flow onto the plate - predict with reasonable accuracy the measured behaviour (Hu and Randolph, 1999). By taking into account the strain softening triggered by the soil backflow during the circular plate penetration, the bearing capacity factor is further reduced by $15-20 \%$ (Hossain and Randolph, 2009a, 2009b) (highlighted in grey in Figure 6), giving improved agreement with the measured response.

\subsection{Monotonic preload}

The effect of monotonic preload, as observed from PF2 and PF2e, is now explored. Figure 7 and Table 5 show the increase in net penetration resistance both in compression, $\Delta q_{\text {net }}^{\mathrm{c}}$, and tension, $\Delta q_{\text {net }}^{\mathrm{t}}$. The centrifuge tests show that, under monotonic preload and after primary consolidation, the net penetration resistance is increased twofold in compression and two-thirds in tension. Since the increase in penetration resistance is essentially proportional to the increase in the strength of the soil participating in the failure mechanism, it results that, after full primary consolidation, the kaolin beneath the footing is up to twice as strong compared to the undrained case.

Figure 8 illustrates the base case penetration resistance, $q_{\text {net }}^{\mathrm{u}}$, compared to the enhanced penetration resistance due to consolidation, $q_{\text {net }}^{\mathrm{c}}$ and $q_{\mathrm{net}}^{\mathrm{t}}$. The results are also compared to the analytical approximation for increased bearing capacity after full primary consolidation derived by Gourvenec et al. (2014) through numerical analysis of modified Cam-Clay soil

7. $\frac{q_{\text {net }}^{\mathrm{c}}}{q_{\text {net }}^{\mathrm{u}}}=1+\frac{\Delta s_{\mathrm{u}}}{s_{\mathrm{u}}}$

where $\Delta s_{\mathrm{u}}$ represents the change in soil strength due to consolidation under preload and is given by 


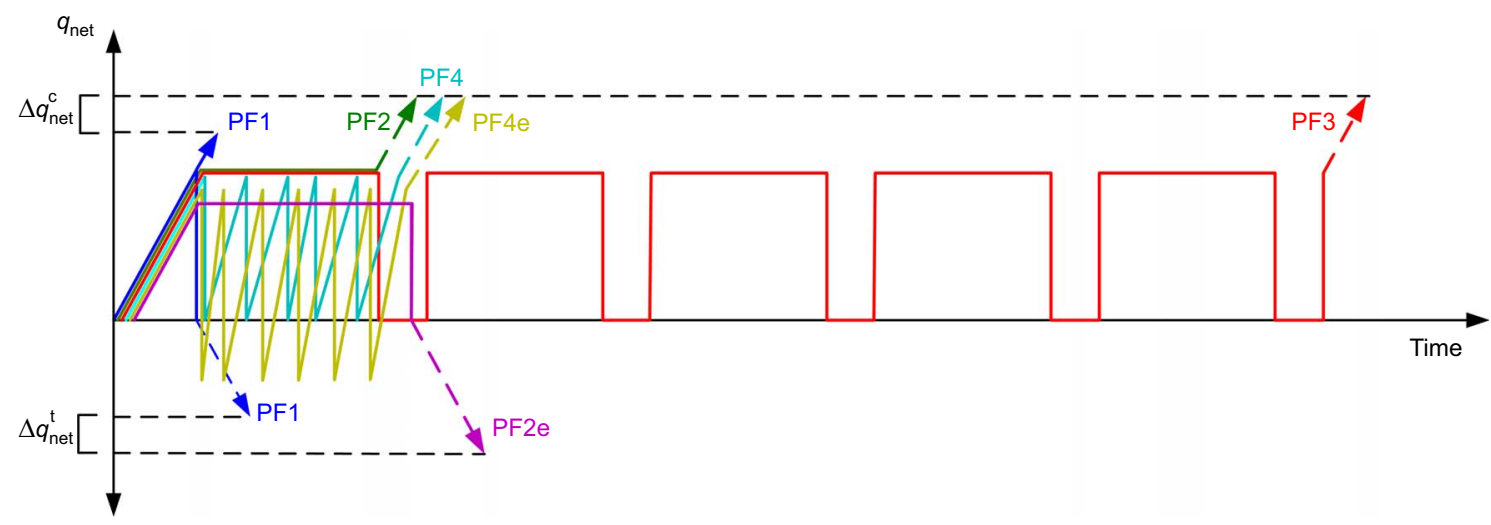

Figure 5. Schematic diagram of centrifuge testing programme: net resistance plotted against time

8. $\Delta s_{\mathrm{u}}=f_{\mathrm{su}} R \Delta q_{\mathrm{pl}}^{\prime}$

where

9. $\Delta q_{\mathrm{pl}}^{\prime}=f_{\sigma}\left(q_{\mathrm{net}}^{\mathrm{u}}+\gamma^{\prime} h_{\text {shaft }}\right)$

where the introduced parameters are: $f_{\text {su }}$, a factor taking into account the non-uniform distribution of the increase in shear strength after consolidation; $R=s_{\mathrm{u}} / \sigma_{\mathrm{v} 0}^{\prime}$, the normally consolidated shear strength ratio ( $\sigma_{\mathrm{v} 0}^{\prime}$ is the in situ vertical effective stress); $h_{\text {shaft }}$, length of shaft penetrated into the soil; $\Delta q_{\mathrm{pl}}^{\prime}$, the increase in consolidation stress following preloading, represented by the net penetration resistance coupled with the pressure of the soil layer above the foundation as a result of full soil backflow around the circular plate.

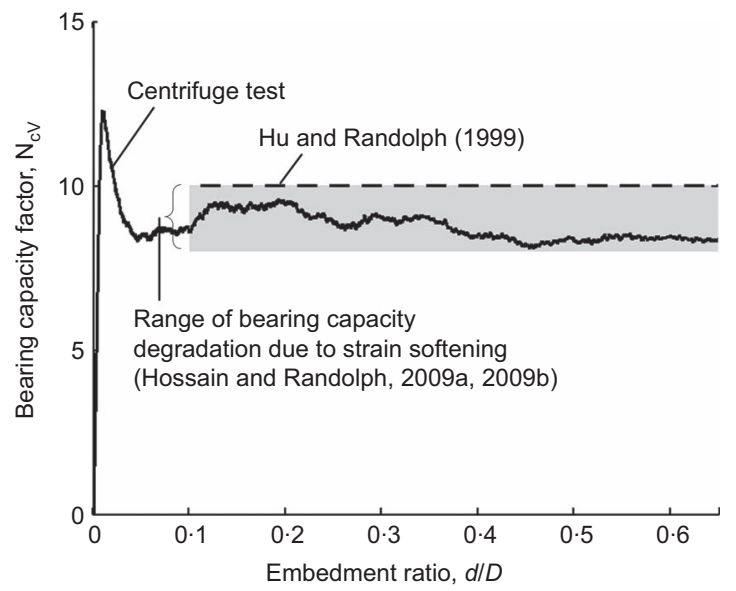

Figure 6. Bearing capacity factor results - comparison with theoretical solutions
The increase in penetration resistance due to monotonic preload as observed in the centrifuge is matched satisfactorily by the analytical approximation.

PF2 is further interpreted by comparing the pore pressure dissipation time history to a numerical study of a buried circular foundation on elastic soil (Gourvenec and Randolph, 2009). Good agreement is achieved by scaling the numerical result using a consolidation coefficient of $c_{\mathrm{v}}=3.3 \mathrm{~m}^{2} /$ year, derived from the piezoball (Figure 9).

\section{Foundation results: cyclic cases}

\subsection{Periodic preload}

The effect of periodic cyclic preload is presented in Figure 10. Each cycle consists of first applying a preload (equal to the

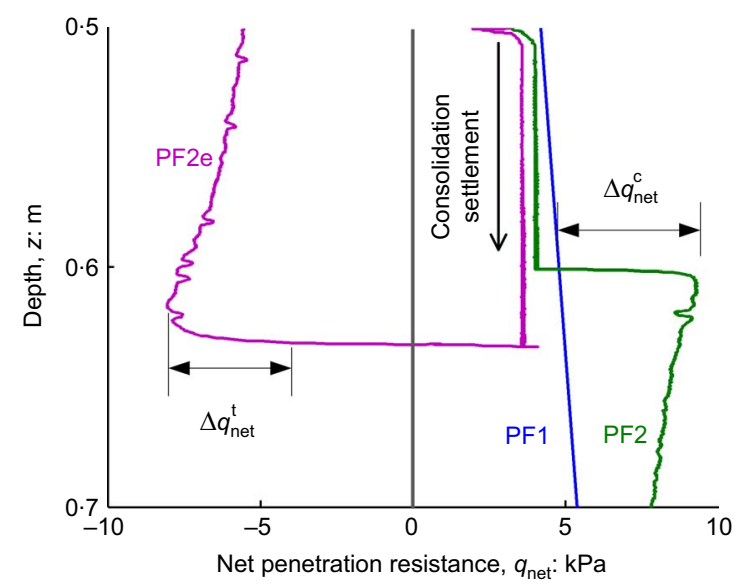

Figure 7. Net penetration resistance in compression and tension during monotonic preload 
Effect of prior loading cycles on vertical bearing capacity of clay Vulpe and White

\begin{tabular}{lcccc} 
& Depth, $z: \mathrm{m}$ & $q_{\text {net,c }}: \mathrm{kPa} / \mathrm{m}^{2}$ & $q_{\text {net,u }}: \mathrm{kPa} / \mathrm{m}^{2}$ & $q_{\text {net, } \mathrm{d} q_{\text {net,u }}}$ \\
\hline PF2 & 0.62 & $9 \cdot 08$ & $4 \cdot 74$ & $1 \cdot 9$ \\
PF2e & 0.62 & $8 \cdot 05$ & $4 \cdot 74$ & $1 \cdot 7$ \\
PF3 & $0 \cdot 68$ & $13 \cdot 00$ & $5 \cdot 13$ & $2 \cdot 5$ \\
PF4 & 0.64 & $8 \cdot 92$ & $4 \cdot 90$ & $1 \cdot 8$ \\
PF4e & $1 \cdot 10$ & $17 \cdot 35$ & $7 \cdot 81$ & $2 \cdot 2$
\end{tabular}

Table 5. Net penetration resistance results

penetration resistance measured at $z=0.5 \mathrm{~m}$ ), followed by full excess pore pressure dissipation, after which the loading is removed and the soil is allowed to swell. After five periodic cycles of preload (PF3), the net penetration resistance of the soil increased to $2 \cdot 5$ times the base case study, $q_{\text {net }}^{\mathrm{u}}$. It can be seen from Figure 10 that the first cycle of preload followed by full primary consolidation results in the highest consolidation settlement. Each preload cycle increases the soil strength by generating excess pore pressure and causing a reduction in moisture content during the subsequent dissipation. All cycles create excess pore pressure, not only the first application of the preload. The changes in load and the resulting shear strain - drive contraction of the soil, as well as the absolute level of applied load.

The excess pore pressure dissipation during the five cycles of periodic preload is summarised in Figure 11(a) and Figure 11(b). The dissipation is presented as a function of dimensionless time factor $T$ and a suitable value of vertical coefficient of consolidation, $c_{\mathrm{v}}$, is fitted to each dissipation stage, where

10. $c_{\mathrm{v}}=\frac{T D^{2}}{t}$

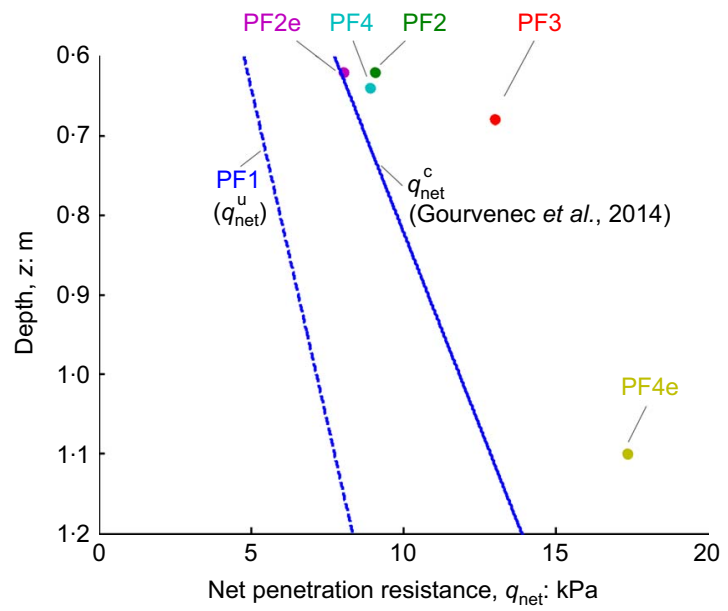

Figure 8. Net penetration resistance - comparison with theoretical solution (Gourvenec et al., 2014) with $t$ representing the time since each change in preload level. A theoretical $T_{50}=0.092$ is chosen from Gourvenec and Randolph (2009) based on their solutions for a buried circular foundation at $d / D=0.5$ in an elastic material governed by Biot-type consolidation.

The back-calculated coefficient of consolidation, $c_{\mathrm{v}}$, increases rapidly over the first few cycles before stabilising (Figure 11(b)). For the first stage, when the moisture content is highest, the low rate of pore water pressure dissipation (i.e. small $c_{\mathrm{v}}$ value) reflects the low stiffness of the soil. After each dissipation stage, the soil underneath the foundation is compressed and the stiffness rises. From the fourth periodic preload cycle onwards, the density and stiffness have converged close to an equilibrium state, with a $c_{\mathrm{v}}$ that is 10-20 times higher than in the initial state. This means that the gain in strength caused by the later cycles occurs much more rapidly than would be estimated from the in situ $c_{\mathrm{v}}$.

\subsection{Continuous cyclic preloading}

Figure 12 shows the effect of one-way continuous cyclic preload (test PF4) on the net penetration resistance. The response is similar to the monotonic preload case $(\mathrm{PF} 2)$ : the net penetration resistance is doubled. Also, a similar pore water

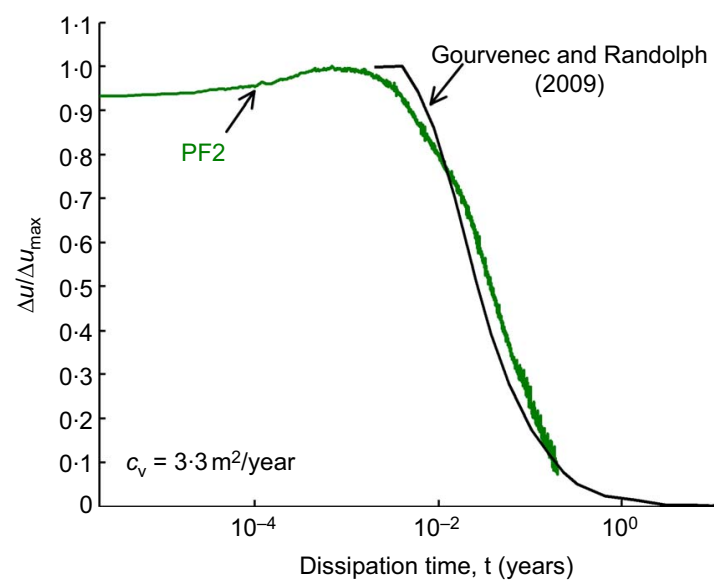

Figure 9. Normalised dissipation curve during monotonic preload 
Effect of prior loading cycles on vertical bearing capacity of clay Vulpe and White

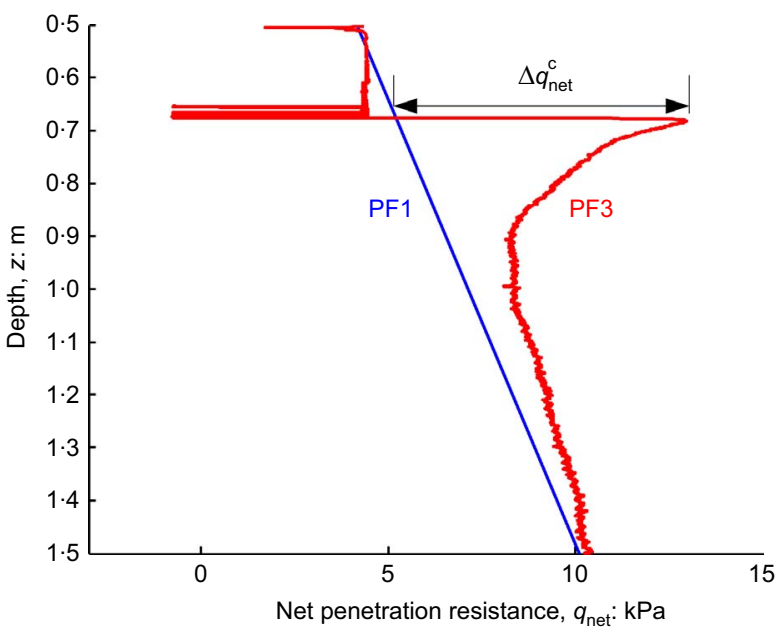

Figure 10. Net penetration resistance in compression during periodic cyclic preload

pressure dissipation rate is achieved, with the PPT recording a similar underlying decay in excess pore pressure, with the response to the cyclic total stress superimposed (Figure 13). Owing to an error in the initial control sequence, the first ten cycles of preload did not reach the correct target loads. However, after the control was restarted at $T=0 \cdot 01$, the remaining 990 cycles followed the specified load pattern.

Although the mean value for the preload during one-way cycling is essentially equivalent to half of the preload subjected to the circular plate in PF2, similar gains in capacity are achieved. This suggests that the shearing during the unloadload cycles compensates for the lower mean applied load.

Under continuous two-way cyclic preload (PF4e), an even greater gain in capacity occurs. There is far greater settlement during pore pressure dissipation and the net penetration resistance is more than doubled compared to the base case study (Figure 14). The two-way nature of the preload cycles means that the mean applied load is zero. However, this is outweighed by the cyclic load component and the shearing effect, which cause a continuous rise in excess pore pressure beneath the foundation until $T=0 \cdot 3$, after which dissipation dominates over generation (Figure 15).

The total settlement under two-way cyclic preload is over six times greater than for monotonic preloading. The first cycles of continuous preload cause significant vertical settlement, and each cycle is clearly distinguishable in Figure 14. As the soil continues to be sheared and densified, the embedment stabilises. Also, the measured excess pore pressure reverts to simply a reflection of the applied total stress, as the elapsed time approaches $T \sim 1$.

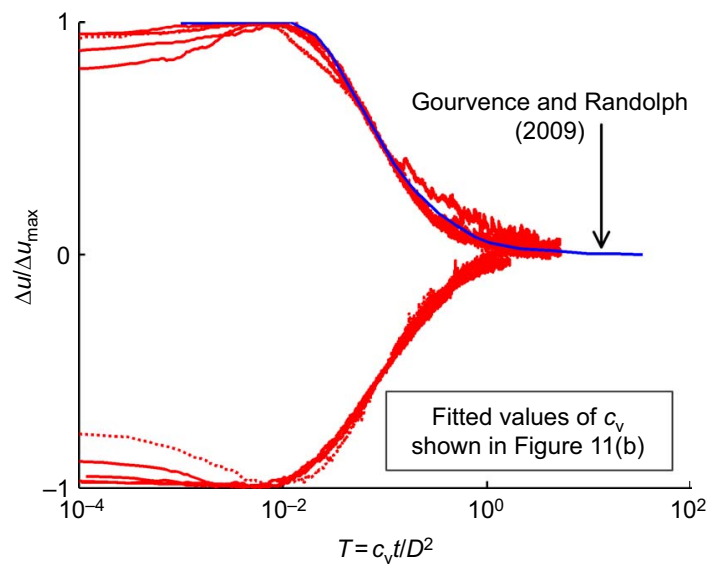

(a)

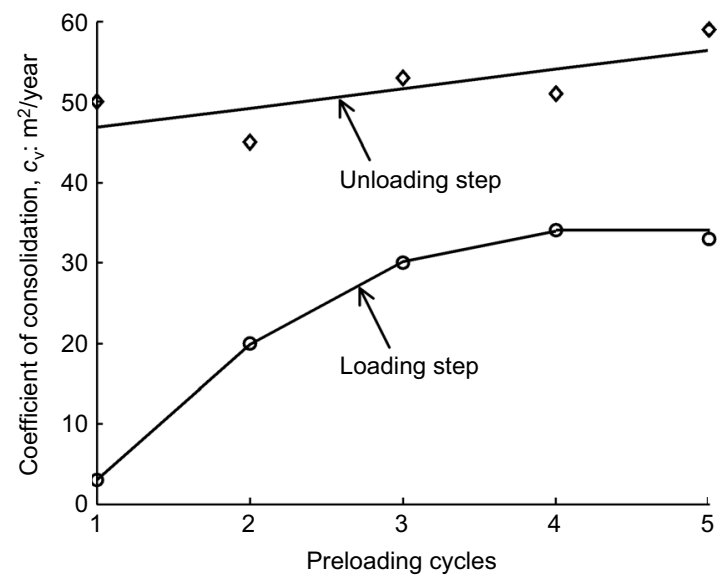

(b)

Figure 11. Cyclic preloading: (a) normalised dissipation curve; (b) fitted coefficient of consolidation

The two continuous cyclic tests show that cyclic loads and the resulting shearing-induced excess pore pressures can be as significant as a static preload in contributing to consolidationenhancement of bearing capacity. Comparison of tests PF2, PF4 and PF4e indicates that

continuous one-way cyclic loading with a given maximum load can create the same consolidation hardening as monotonic loading at the same level, in the same time frame

continuous two-way cyclic loading can create greater cyclic settlement and increased enhancement of bearing capacity compared to monotonic loading at the same level, in the same time frame.

The centrifuge test results mirror conventional pore pressure contour diagrams (i.e. $S-N$ curves) derived from consolidated, 
Effect of prior loading cycles on vertical bearing capacity of clay Vulpe and White

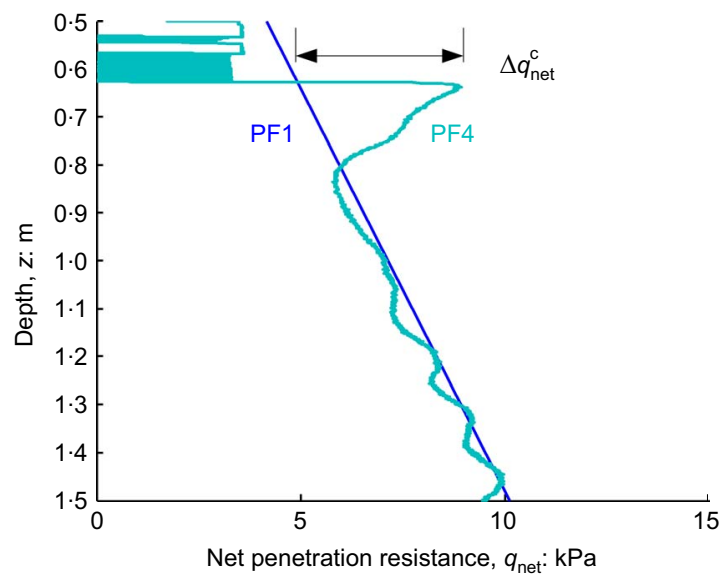

Figure 12. Net penetration resistance in compression during oneway cyclic preload

undrained, triaxial compression tests in that two-way loading creates higher excess pore pressure (Koutsoftas, 1978). The additional observation is that permitting pore pressure dissipation converts these increased pore pressures into an increase in the gain in soil undrained strength and bearing capacity.

The consolidation-induced increase in bearing capacity from the monotonic case in this study shows good agreement with a simple prediction method (Gourvenec et al., 2014). A further challenge is to predict the influence of cycles of loading, and the resulting gain in bearing capacity. These model tests show that both continuous and periodic cycles create an additional significant enhancement of bearing capacity (see Figure 8).

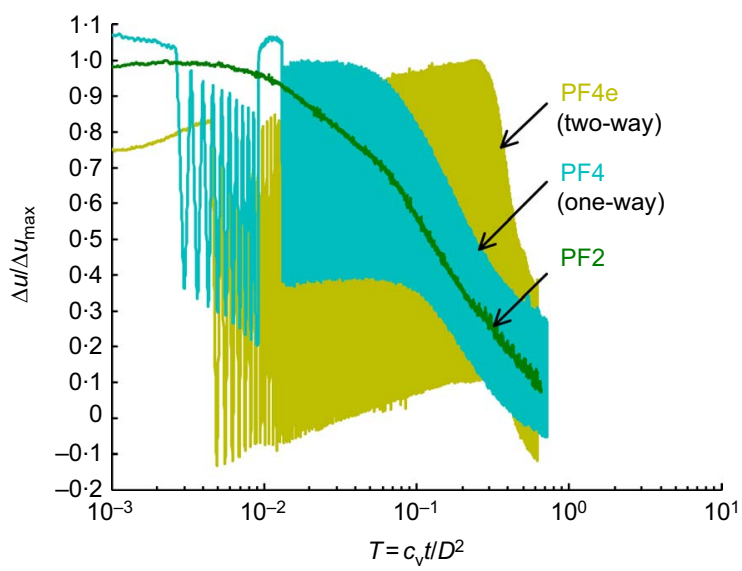

Figure 13. Normalised dissipation curve during cyclic preload comparison with monotonic preload

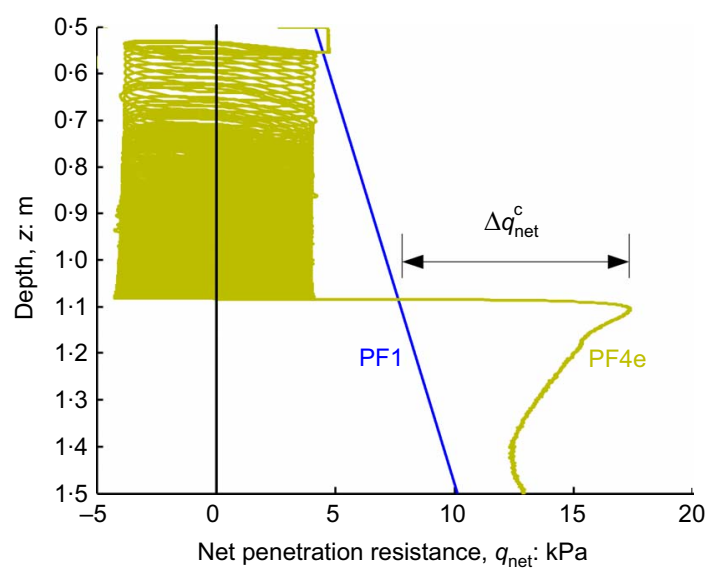

Figure 14. Net penetration resistance in compression during twoway cyclic preload

\section{Conclusion}

The effect of monotonic and cyclic vertical preload on the strength of a soft clay was investigated by means of centrifuge testing. The overall conclusion is that, although monotonic vertical preload is known to generate a significant increase in bearing capacity, this increase is enhanced further if the preloading is cyclic. It was found that the undrained strength of a foundation can double, after being subjected to drained cycles of vertical preload, with two-way cyclic loading generating a greater gain than one-way loading. The explanation for these trends is that, during the cyclic preloading, if sufficient time for drainage is permitted, the soil contracts and the undrained strength increases. Two-way loading is more effective at pore pressure generation and densification than one-way loading.

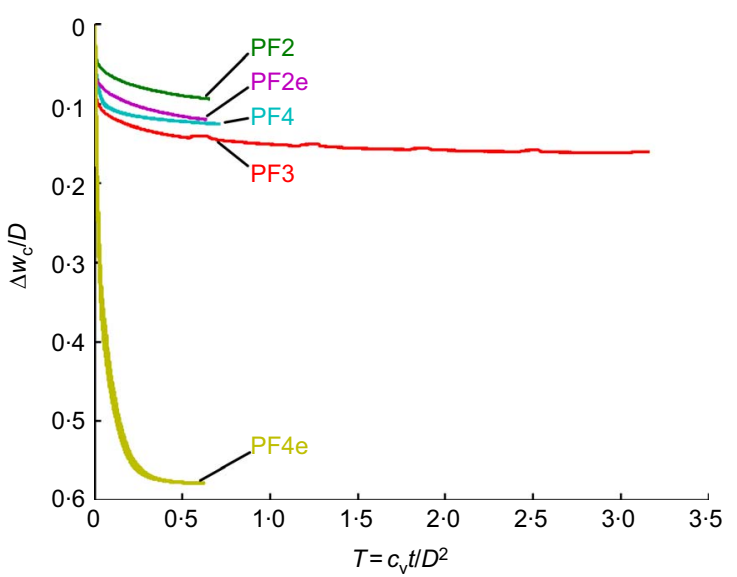

Figure 15. Consolidation settlement curves 
International Journal of Physical Modelling in Geotechnics Volume 14 Issue 4
Effect of prior loading cycles on vertical bearing capacity of clay Vulpe and White
The excess pore water pressure dissipates at similar rates for both monotonic and continuous cyclic preload. For periodic or drained cycles of preload, successive episodes of dissipation and strength gain become more rapid. The back-calculated consolidation coefficients indicate a 10-20 times increase in $c_{\mathrm{v}}$ after only five cycles.

\section{Acknowledgements}

This work forms part of the activities of the Centre for Offshore Foundation Systems (COFS), currently supported as a node of the Australian Research Council Centre of Excellence for Geotechnical Science and Engineering and as a Centre of Excellence by the Lloyd's Register Foundation. The second author is supported by Shell Australia. The authors would like to thank Manuel Palacios, chief centrifuge technician, for his assistance during tests.

\section{REFERENCES}

Andersen KH (2004) Cyclic clay data for foundation design of structures subjected to wave loading. Proceedings of the International Conference on Cyclic Behaviour of Soils and Liquefaction Phenomena (CBS04), Bochum, Germany, pp. 371-387.

Andersen KH (2009) Bearing capacity under cyclic loading offshore, along the coast, and on land. The 21st Bjerrum Lecture presented in Oslo, 23 November 2007. Canadian Geotechnical Journal 46(5): 513-535.

Bjerrum L (1973) Geotechnical problems involved in foundations of structures in the North Sea. Géotechnique 23(3): 319-358, http://dx.doi.org/10.1680/geot.1973.23.3. 319.

Bransby MF (2002) The undrained inclined load capacity of shallow foundations after consolidation under vertical loads. Proceedings of the 8th Conference on Numerical Models in Geomechanics (NUMOG), Rome, Italy, pp. 431-437.

Butcher AP, Powell JJM and Skinner HD (eds) (2006) Proceedings of the International Conference on the Reuse of Foundations for Urban Sites. BRE Press, Watford, UK.

Chapman T, Anderson S and Windle J (2007) Reuse of Foundations. Ciria, London, UK, Ciria 653.

Chen W (2005) Uniaxial Behaviour of Suction Caissons in Soft Deposits in Deepwater. PhD thesis, University of Western Australia, Perth, Australia.

Chung SF and Randolph MF (2004) Penetration resistance in soft clay for different shaped penetrometers. Proceedings of the 2nd International Conference on Geotechnical and Geophysical Site Characterization - ISC'2, Porto. Millpress, Rotterdam, the Netherlands, pp. 671-678.

Colreavy C, O'Loughlin CD, Long M, Boylan N and Ward D (2010) Field experience of the piezoball in soft clay. Proceedings of the 2nd International Symposium on Cone Penetration Testing, Huntington Beach, CA, USA, Technical Papers, Session 1: Equipment and Procedures, pp. 1-15.
De Catania S, Breen J, Gaudin C and White DJ (2010) Development of multiple-axis actuator control system. Proceedings of the 7th International Conference on Physical Modelling in Geotechnics, Zurich, Switzerland, pp. 325-330.

France JW and Sangrey DA (1977) Effects of drainage in the repeated loading of clays. Journal of the Geotechnical Engineering Division, ASCE 103(GT7): 769-785.

Finnie IM and Randolph MF (1994) Bearing response of shallow foundations on uncemented calcareous soil. Proceedings of the International Conference Centrifuge '94, Singapore, vol. 1, pp. 535-540.

Gaudin C, White DJ, Boylan N et al. (2009) A wireless data acquisition system for centrifuge model testing. Measurement Science and Technology 20(9): 095709.

Gourvenec S and Randolph MF (2009) Effect of foundation embedment and soil properties on consolidation response. Proceedings of the International Conference on Soil Mechanics and Geotechnical Engineering (ICSMGE), Alexandria, Egypt, pp. 638-641.

Gourvenec SM, Acosta-Martinez HE and Randolph MF (2009) Experimental study of uplift resistance of shallow skirted foundations in clay under transient and sustained concentric loading. Géotechnique 59(6): 525-537, http://dx. doi.org/10.1680/geot.9.P.027.

Gourvenec SM, Vulpe C and Murthy TG (2014) A method for predicting the consolidated undrained bearing capacity of shallow foundations. Géotechnique 64(3): 215-225, http:// dx.doi.org/10.1680/geot.13.P.101.

Hodder M, White DJ and Cassidy MJ (2013) An effective stress framework for the variation in penetration resistance due to episodes of remoulding and reconsolidation. Géotechnique 63(1): 30-43, http://dx.doi.org/10.1680/geot.9. P.145.

Hossain MS and Randolph MF (2009a) New mechanism-based design approach for spudcan foundations on single layer clay. Journal of Geotechnical and Geoenvironmental Engineering 135(9): 1264-1274.

Hossain MS and Randolph MF (2009b) Effect of strain rate and strain softening on the penetration resistance of spudcan foundations on clay. Journal of Geotechnical and Geoenvironmental Engineering 9(3): 122-132.

Hu Y and Randolph MF (1999) Plate-penetrometer penetration into NC soil using H-adaptive FE method. In Proceedings of the 7th International Symposium on Numerical Methods (NUMOG VII), Graz, Austria. Taylor \& Francis, London, UK, pp. 501-506.

Hyde AEL and Ward SJ (1986) The effect of cyclic loading on the undrained shear strength of a silty clay. Marine Geotechnology 6(3): 299-314, http://dx.doi.org/10.1080/ 10641198609388192.

Koutsoftas DC (1978) Effect of cyclic loads on undrained strength of two marine clays. Journal of the Geotechnical Engineering Division, ASCE 104(5): 609-620. 
Effect of prior loading cycles on vertical bearing capacity of clay Vulpe and White
Low HE, Randolph MF and Kelleher P (2007) Comparison of pore pressure generation and dissipation rates from cone and ball penetrometers. Proceedings of the 6th International Conference of the Society for Underwater Technology, Offshore Site Investigation and Geotechnics (SUT-OSIG), London, UK, pp. 547-556.

Low HE, Lunne T, Andersen KH et al. (2010) Estimation of intact and remoulded undrained shear strengths from penetration tests in soft clays. Géotechnique 60(11): 843-859, http://dx. doi.org/10.1680/geot.9.P.017.

Randolph MF and Hope S (2004) Effect of cone velocity on cone resistance and excess pore pressures. IS OsakaEngineering Practice and Performance of Soft Deposits, Osaka, Japan, pp. 147-152.

Randolph MF, Jewell RJ, Stone KJL and Brown TA (1991) Establishing a new centrifuge facility. Proceedings of the International Conference on Centrifuge Modelling Centrifuge 91, Boulder, CO, USA, pp. 3-9.

Togrol E and Güler E (1984) Effect of repeated loading on the strength of clay. Soil Dynamics and Earthquake Engineering 3(4): 184-190.
Stewart D (1992) Lateral Loading on Piles due to Simulated Embankment Construction. PhD thesis, University of Western Australia, Crawley, Australia.

van Eekelen HAM and Potts DM (1978) The behaviour of Drammen Clay under cyclic loading. Géotechnique 28(2): 173-196. See http://dx.doi.org/10.1680/geot.1978.28. 2.173 .

Watson PG and Humpheson C (2007) Foundation design and installation of the Yolla A platform. In Proceedings of Offshore Site Investigation and Geotechnics 2007. Confronting New Challenges and Sharing Knowledge (Pourshoushtari M (ed.)). Society for Underwater Technology, London, UK, pp. 399-412.

White DJ and Hodder M (2010) A simple model for the effect on soil strength of episodes of remoulding and reconsolidation. Canadian Geotechnical Journal 47: 821826.

Zdravkovic L, Potts DM and Jackson C (2003) Numerical study of the effect of preloading on undrained bearing capacity. International Journal of Geomechanics, ASCE 3(1): $1-10$.

\section{WHAT DO YOU THINK?}

To discuss this paper, please email up to 500 words to the editor at journals@ice.org.uk. Your contribution will be forwarded to the author(s) for a reply and, if considered appropriate by the editorial panel, will be published as discussion in a future issue of the journal.

Proceedings journals rely entirely on contributions sent in by civil engineering professionals, academics and students. Papers should be 2000-5000 words long (briefing papers should be $1000-2000$ words long), with adequate illustrations and references. You can submit your paper online via www.icevirtuallibrary.com/content/journals, where you will also find detailed author guidelines. 